\title{
Salinity and relative humidity: climatological relevance and metrological needs
}

\author{
Rainer Feistel \\ Leibniz Institute for Baltic Sea Research, 18119 Warnemünde, Germany
}

\begin{abstract}
Water plays the leading thermodynamic role in Earth's "steam engine" climate. Followed by clouds and $\mathrm{CO}_{2}$, water vapour in the atmosphere is dominating the greenhouse effect. Evaporation from the ocean surface is the main route of energy export from the ocean, the rate of which is known with poor $20 \%$ uncertainty only. Regional climatic trends in evaporation and precipitation are reflected in small changes of ocean surface salinity.

Observational data of salinity and relative humidity need to be globally comparable within requisite uncertainties over decades and centuries, but both quantities rely on century-old provisional standards of unclear stability, or on ambiguous definitions. This increasingly urgent and long-pending problem can only be solved by proper metrological traceability to the International System of Units (SI). Consistent with such SI-based definitions, state-of-the-art correlation equations for thermophysical properties of water, seawater, ice and humid air such as those available from the recent oceanographic standard TEOS-10 need to be developed and adopted as joint international standards for all branches of climate research, in oceanography, meteorology and glaciology for data analysis and numerical models.

The SCOR/IAPWS/IAPSO Joint Committee on the Properties of Seawater JCS is targeting at these aims in cooperation with BIPM, WMO and other international bodies.
\end{abstract}

\section{Section: TECHNICAL NOTE}

Keywords: TEOS-10; salinity; relative humidity; metrology; SI-traceability; climatology; hydrological cycle

Citation: Rainer Feistel, Salinity and relative humidity: climatological relevance and metrological needs, Acta IMEKO, vol. 4, no. 4, article 11, November 2015, identifier: IMEKO-ACTA-04 (2015)-04-11

Editor: Paolo Carbone, University of Perugia, Italy

Received September 29, 2014; In final form September 29, 2014; Published December 2015

Copyright: @ 2015 IMEKO. This is an open-access article distributed under the terms of the Creative Commons Attribution 3.0 License, which permits unrestricted use, distribution, and reproduction in any medium, provided the original author and source are credited

Corresponding author: Rainer Feistel, e-mail: rainer.feistel@io-warnemuende.de

\section{INTRODUCTION}

Between 1910 and 1945, global air temperatures increased by about $0.5{ }^{\circ} \mathrm{C}$, followed by a stagnation period of roughly 30 years, and by another rise by $0.5^{\circ} \mathrm{C}$ within 30 years, until quite recently a sudden "hiatus" of global warming was discovered. Neither the obvious frequency nor the tipping points of this staircase are explained, let alone predicted, by global climate models. Rather, the hunt is open for finding "the lost heat" [1]. Among the top "suspects" is ocean-atmosphere interaction with anomalies in humidity and salinity; Section 4 will return to this point.

Another hot favourite is uncertainty of observational data [2]. A rule-of-thumb calculation tells us that warming an atmospheric mass of $10^{4} \mathrm{~kg} / \mathrm{m}^{2}$ by $0.5{ }^{\circ} \mathrm{C}$ within 30 years requires a mean heat flux of about $5 \mathrm{~mW} / \mathrm{m}^{2}$. This estimate may be low by a factor of 10 if the ocean surface is included, but that is another question. On the other hand, oceanic evaporation of $1200 \mathrm{~mm} / \mathrm{yr}$ exports $100 \mathrm{~W} / \mathrm{m}^{2}$ of latent heat to the atmosphere. A typical meteorological uncertainty of $1 \%$ rh of the typical ocean-surface relative humidity (RH) of $80 \%$ rh implies an uncertainty of $6 \mathrm{~W} / \mathrm{m}^{2}$ of the latent heat flux [3]. Thus, the systematic signal needed to detect the hiatus is 1000 times below the noise level of the data available. In fact the uncertainty of the global latent heat flux amounts to as much as $30 \mathrm{~W} / \mathrm{m}^{2}$ for various other reasons [4] even if the uncertainty of the global $\mathrm{RH}$ average may likely be less than $1 \%$ rh. Atmospheric water flux is a perfect hideout for "the lost heat".

The hydrological cycle is a prominent example for metrological deficiencies in climatology, meteorology and oceanography. Scientific analysis must rely on century-long data series of high accuracy and stability, world-wide homogeneity, without spurious trends or technological artefacts, which is by 
no means granted for the records we possess since meteorological and oceanographic data started to be collected systematically. Improvement is urgently needed.

Anomalies of evaporation and precipitation leave their footprints behind in ocean salinity [5] which can be measured much more precisely than relative humidity or heat flux. But, salinity measurements are not (yet) traceable to the International System of Units, SI [6] and tiny drifts of the metrological reference materials may remain undetectable, see Section 3.

The introduction of the new Thermodynamic Equation of Seawater 2010, TEOS-10 [7] has addressed a number of open questions of salinity measurement and of the definition of relative humidity, as briefly reviewed in Section 2. But this work has also shed new light on further fundamental problems which may be solved in close cooperation of a newly established SCOR $^{1} /$ IAPWS $^{2} /$ IAPSO $^{3}$ Joint Committee on the Properties of Seawater, JCS, with international bodies such as BIPM ${ }^{4}$ and $\mathrm{WMO}^{5}$, see Section 5. In a recent series of four papers [8], metrological challenges for measurements of key climatological observables are reviewed and future actions are suggested for practical solutions, Section 6 .

\section{SEAWATER STANDARD TEOS-10}

TEOS-10, the Thermodynamic Equation of Seawater 2010 [7], was adopted as an international standard for oceanography by the IOC $^{6}$ in Paris in 2009 and by the $\mathrm{IUGG}^{7}$ in Melbourne in 2011. It provides thermodynamic properties of water, ice, seawater and humid air in a mutually consistent way. Its novel axiomatic approach is based on four thermodynamic potentials, subsequently endorsed as IAPWS documents in 2006, 2008, 2009 and 2010, from which various properties of the pure substances, their mixtures, phase equilibria and composites can be formally derived by mathematical or numerical methods [9], see Figure 1.

For the first time after a century of international oceanographic standards [10], TEOS-10 makes use of a chemical composition model for sea salt dissolved in IAPSO Standard Seawater (SSW), the standard reference material for oceanographic salinity measurements specified by the Practical Salinity Scale of 1978 (PSS-78). The related new ReferenceComposition Salinity Scale [11] provides a conversion formula for PSS-78 data but additionally permits systematic studies of seawater composition anomalies [12].

TEOS-10 is highly accurate. Within their common ranges of validity, TEOS-10 is consistent with the CIPM-2001 equation for the density of liquid water [13], [14] and with the CIPM2007 equation for the density of humid air [15] which are

\footnotetext{
${ }^{1}$ SCOR: Scientific Committee on Oceanic Research, http://www.scor-int.org 2 IAPWS: International Association for the Properties of Water and Steam, http://www.iapws.org

${ }^{3}$ IAPSO: International Association for the Physical Sciences of the Oceans, http://iapso.iugg.org

${ }_{4}$ BIPM: Bureau International des Poids et Mesures, http://www.bipm.org

${ }^{5}$ WMO: World Meteorological Organization, http://www.wmo.int

${ }^{6}$ IOC: Intergovernmental Oceanographic Commission of UNESCO,

http://ioc-unesco.org

7 IUGG: International Union of Geodesy and Geophysics,

http://www.iugg.org
}

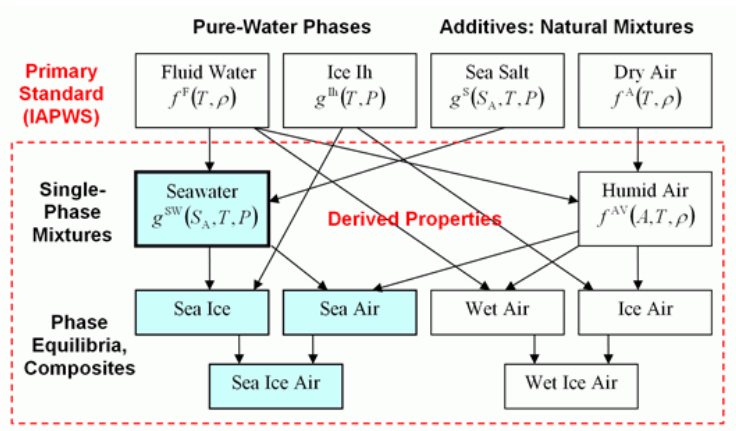

Figure 1. Axiomatic structure of TEOS-10. Four thermodynamic potentials (top row) contain all empirical coefficients and permit the calculation of derived properties in a consistent, independent and complete way.

recommended for metrology by the CIPM ${ }^{8}$. TEOS-10 results for the ice point and for the sublimation pressure are the most accurate values currently available [16]. Entropy and enthalpy of seawater, ice and humid air available from TEOS-10 provide precise values of the oceanic heat content [17] and for the latent heat of evaporation and of freezing of seawater [18]. Relative fugacity calculated from TEOS-10 is physically more suitable than relative humidity defined by WMO [19] for the description of non-equilibrium thermodynamic forces at the oceanatmosphere interface [3], [16].

TEOS-10 was developed in close cooperation between the IAPWS Subcommittee on Seawater, SCSW, that was established at the $15^{\text {th }}$ International Conference on the Properties of Water and Steam in 2008 in Berlin, Germany, and the SCOR/IAPSO Working Group 127 on Thermodynamics and Equation of State of Seawater, established in 2005 in Cairns, Australia, and disbanded in 2011 in accordance with the rules governing SCOR/IAPSO Working Groups [10]. WG 127 was chaired by Trevor McDougall, Hobart, Australia, and SCSW by Rainer Feistel, Warnemünde, Germany.

\section{SALINITY AND RELATIVE HUMIDITY}

Conductance measurements relative to a standard reference solution offer higher resolution than SI-traceable "absolute" measurements in conductance cells. The difference between the two is crucial for oceanographic density calculations, and so world-wide salinity measurements are carried out with conductivity sensors calibrated with respect to certified SSW specimen, as defined by PSS-78. This excellent resolution and comparability prevents the false detection of spurious, virtually significant density gradients in the world ocean but comes at the risk of rising uncertainties in long-term trends [6]. Moreover, conductivity measurements alone cannot detect composition anomalies of the solute that may affect the seawater density, such as dissolved silicate in the deep Pacific [20].

SI-traceability is indispensable for the detection of tiny but climatologically relevant long-term salinity trends. Among the surrogate measurands that may substitute conductance for this purpose, density is the most promising candidate, but the

${ }^{8}$ CIPM: Comité International des Poids et Mesures, http://www.bipm.org/en/committees/cipm/ 
intended transition causes numerous practical, technological and metrological problems to be addressed, see Section 6 .

Relative humidity is defined by WMO and $\mathrm{ASHRAE}^{9}$ as the partial pressure of water vapour divided by the same quantity at saturation at the same temperature and pressure. However, several meteorological textbooks, climatological studies or $\mathrm{IUPAC}^{10}$ offer alternative and mutually inconsistent definitions. Most of the definitions fail under certain conditions, for example for humid air in equilibrium with concentrated solutions at low pressures. Moreover, different correlation equations for the calculation of dewpoint temperatures or saturation pressures are in practical use, often without explicit specification of uncertainty or range of validity.

In order to harmonise this variety and to ensure comparability and stability of measurements, the Working Group "Humidity" of CIPM-CCT"11 is investigating suitable options available for this purpose. Among those is relative fugacity [16], [18] which properly describes the thermodynamic driving forces in non-equilibrium situations and naturally covers conditions where other definitions cease to exist. TEOS-10 is an international standard that offers accurate equations for the calculation of the fugacity of water in humid air [21].

\section{CLIMATOLOGICAL RELEVANCE}

Water is a key player in Earth's climate dynamics; Heinrich Hertz in 1885 was perhaps the first who painted the physical picture of climate as a "gigantic steam engine" [22]. Processes involving water in the atmosphere are very complex, theoretically and observationally demanding, and subject to substantial uncertainties [4]. The fundamental energy conveyor of our climate is the hydrological cycle rather than the radiative " $\mathrm{CO}_{2}$ greenhouse" balance often debated in public.

Water vapour in the atmosphere accounts for $50-60 \%$ of the terrestrial greenhouse effect, in contrast to only about 20 $25 \%$ due to carbon dioxide, $\mathrm{CO}_{2}$. Atmospheric $\mathrm{RH}$ also controls the oceanic export of latent heat as well as the formation and distribution of clouds; the latter may contribute another 10 - $25 \%$ to the greenhouse warming. Estimates for the latent-heat fraction of air-sea energy exchange vary between 45 and $90 \%$.

Trends in global distributions of humidity, latent heat flux, evaporation and precipitation are closely connected with small but precisely measurable systematic changes in sea-surface salinities [5]. The latter govern oceanic convection processes which may deposit vast amounts of heat in the abyss [1].

As a result of global warming, the amount of tropospheric water is increasing which in turn amplifies the temperature rise via a positive feedback loop, known as the "runaway greenhouse" effect [23]. In contrast, $\mathrm{RH}$ over the oceans is rather constant at values of about $80 \%$ rh, almost independently of region, season, or atmospheric warming.

9 ASHRAE: American Society of Heating, Refrigerating and Air-Conditioning Engineers, http://www.ashrae.org/

${ }^{10}$ IUPAC: International Union of Pure and Applied Chemistry, http://www.iupac.org

11 CCT: CIPM Consultative Committee on Thermometry, http://www.bipm.org/en/committees/cc/cct/
Similarly, no significant trend of the total cloud cover or albedo could be detected yet.

The fundamental physical causes for this constancy remain elusive [23] but strong feedback mechanisms between the two "adiabatic invariants" of climate change may be assumed [3], [24]. Day-time clouds form the main "input valve" for solar irradiation while surface RH regulates the ocean's cooling by evaporation. The self-organised loop is closed by the formation of clouds, governed by the amount of atmospheric moisture which originates to $90 \%$ from the ocean. The signature of this process is hidden in the fluctuation spectra of cloudiness and of relative humidity at the sea surface. The characteristic time scales of this feedback are well known and rather short; the residence time of solar energy in the ocean surface layer is between 60 and 90 days, that of water in the troposphere is about 8 days, and that of water in clouds is just 1 hour. Short relaxation times indicate high dynamic stability against external fluctuations. Small changes of this feedback may easily amplify or compensate effects caused by $\mathrm{CO}_{2}$ or other atmospheric perturbations.

In contrast to the temperature, small systematic anomalies of the chemical and isotopic compositions of the natural fluid mixtures "seawater" and "humid air" may go almost unnoticed even though they represent key indicators for severe implications of climate change.

\section{JOINT COMMITTEE ON SEAWATER}

As long as the understanding of the climate attractor and the predictive capabilities of global circulation models remain insufficient, careful long-term observations extending over decades remain indispensable. However, this urgent need is in striking discrepancy to the fact that the formal definitions and the measurement practice of seawater salinity and atmospheric $\mathrm{RH}$ include century-old provisional and ambiguous definitions, in part without proper metrological traceability to the SI. Such problems were emphasised at the 2010 WMO-BIPM Workshop on measurement challenges for global observation systems for climate change monitoring in Geneva [25].

To overcome this situation and to improve long-term stability and consistency of measurement results, initial meetings between representatives of BIPM and IAPWS took place at the BIPM in August 2011 and in February 2012, see Figure 2. As a result, a joint effort of IAPWS, BIPM, SCOR, IAPSO and WMO has been envisaged to address metrological challenges for measurements of certain key climatological observables, including oceanic salinity and atmospheric relative humidity [8]. In this cooperation of international bodies,

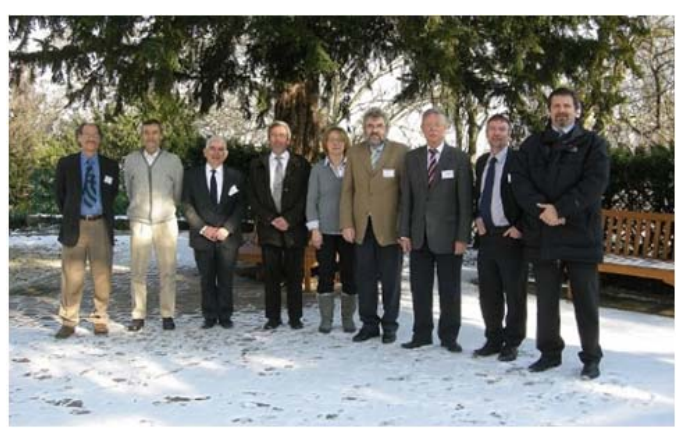

Figure 2. Participants of the BIPM-IAPWS Meeting on 7 February 2012 at the BIPM headquarter, Pavillon de Breteuil at Sèvres near Paris, from left to right: Dan Friend, Karol Daucik, Jeff Cooper, Alain Picard, Petra Spitzer, Rainer Feistel, Michael Kühne, Andy Henson, Robert Wielgosz. 
IAPWS may provide highly accurate correlation equations that relate the problematic quantities to suitable surrogate measurands and to other relevant properties, consistent with the TEOS-10 equations.

BIPM may support this aim by the endorsement and recommendation of suitable uniform definitions and related metrological standards in the framework of the SI. SCOR, IAPSO and WMO may guide and support the adoption of the new equations and standards in the atmospheric and oceanographic scientific and technical communities.

This important and demanding activity will be coordinated by the Joint Committee on the Properties of Seawater ${ }^{12}$ (JCS) that was founded at the IAPWS Meeting in October 2012 in Boulder, Colorado. Membership and terms of reference were identified in September 2013 during a joint IAPWS-BIPM workshop held at the $16^{\text {th }}$ International Conference on the Properties of Water and Steam in Greenwich, UK. In return, JCS representatives attended the 2014 meetings of CCQM ${ }^{13}$ and CCT at the BIPM in Sèvres. JCS is chaired by Rich Pawlowicz, Vancouver, Canada.

\section{INTENDED ACTIVITIES}

JCS in cooperation with CCQM is working toward an oceanic salinity definition traceable to the SI. This development may include several subsequent steps:

Step 1: Define salinity as the mass fraction of solute. This was already done by the formal introduction of "Absolute Salinity" in the framework of TEOS-10 [11], [12].

Step 2: Calculate this mass fraction for a chemical reference model. The Reference Composition introduced in 2008 [11] satisfies this requirement.

Step 3: By experimental and theoretical data, relate Step 2 to SI-traceable surrogate measurands of sufficient accuracy: This was achieved by the construction of the TEOS-10 equation of state [26] which relates seawater density to the Absolute Salinity, and by studies that demonstrate the insensitivity of this relation with respect to small composition anomalies [12], [20], [27], colloquially known as "Millero's rule" [28]. Seawater density relative to pure-water density can be measured in the laboratory within an uncertainty of less than 3 ppm [29], [30], [31], which is sufficiently accurate for oceanography.

Step 4: Officially endorse the relation of Step 3 as a standard equation. The introduction of TEOS-10 as an international standard for oceanography by IOC and IUGG served this purpose.

Step 5: Produce reference materials of certified salinity based on the relation defined in Step 4. Work on this task is in progress. Among the various practical problems involved is the stability of certified density in distributed and stored ampoules of Standard Seawater.

Step 6: Calibrate routine instruments (whatever quantity they actually measure) with the reference materials provided by Step 5. It is planned that conventional bathysondes (CTD) equipped with conductivity sensors will be calibrated with respect to

12 JCS: SCOR/IAPWS/IAPSO Joint Committee on the Properties of Seawater, http://www.teos-10.org/JCS.htm

${ }_{13}$ CCQM: CIPM Consultative Committee for Amount of Substance, http://www.bipm.org/en/committees/cc/ccqm/ density rather than to salinity. Other studies of external groups investigate the sea-going use of in-situ sensors that measure density or refractive index rather than conductivity.

Step 7: To support Step 6, add auxiliary standard equations, such as between salinity and conductivity, or between density and refractive index. These tools may permit an easy in-situ detection of seawater composition anomalies but will in advance require extensive future laboratory work.

IAPWS supports external activities of this kind by Certified Research Needs [32].

CCT in cooperation with JCS is working toward a new definition of relative humidity. A tentative series of actions is suggested here, similar to those of salinity, but likely the practice of future scientific and technological developments may take other roads.

Step 1: Develop an SI definition of relative humidity. A promising candidate for this quantity is relative fugacity to which all other RH definitions in practical use (by WMO, ASHRAE, etc.) may be considered as suitable proxies.

Step 2: Calculate the quantity of Step 1 for a chemical reference model. The CIPM stoichiometric model of dry air [15] is consistent with the TEOS-10 equation of state for humid air. TEOS-10 permits the calculation of fugacity and relative fugacity, but more work is needed here on the details of, e.g., the roles of varying amounts of $\mathrm{CO}_{2}$ or of the dissolution of air in water.

Step 3: By experimental and theoretical data, relate Step 2 to SI-traceable surrogate measurands of sufficient accuracy. This may in a first approach be achieved by the TEOS-10 equation for humid air but may require further refinement in the future.

Step 4: Officially endorse Step 3 as a standard equation. This may take the form of a CIPM equation for the relative humidity or relative fugacity.

Step 5: Produce reference materials or calibration devices (such as saturated solutions or humidity generators) of certified RH based on Step 4.

Step 6: Calibrate routine instruments (such as the various humidity sensors available) against the standards specified in Step 5.

\section{CONCLUSIONS}

Water in different phases and mixtures is a key element of the climate system. Long-term chemical and isotopic changes of oceanic and atmospheric water mixtures must be monitored regularly and precisely. Mutual consistency and comparability of observational measurement results are indispensable. Future SIbased definitions of seawater salinity and relative humidity are necessary and long overdue. IAPWS formulations for climatologically relevant quantities may support upcoming definitions and measurement standards developed by the BIPM. There is a wide and important field for IAPWS as a standard-developing organisation that is specialised on aqueous systems to engage in climate research, as there is for BIPM to further engage in climate research to ensure world-wide uniformity of measurements and their traceability to the SI.

\section{REFERENCES}

[1] X. Chen, K.-K. Tung, Varying planetary heat sink led to globalwarming slowdown and acceleration, Science 345(2014), pp. 897 903.

[2] J. Curry, Uncertain temperature trend, Nature Geosci. 7(2014), pp. 83-84. 
[3] R. Feistel, W. Ebeling, Physics of Self-Organization and Evolution, Wiley-VCH, Weinheim, 2011, ISBN 978-3-52740963-1.

[4] S.A. Josey, S. Gulev, L. Yu, "Exchanges through the ocean surface", in: Ocean Circulation and Climate. A 21 $1^{\text {st }}$ Century Perspective. G. Siedler, S.M. Griffies, J. Gould, J.A. Church (editors). Elsevier, Amsterdam, 2013, ISBN: 978-0-12-391851-2, pp. 115-140.

[5] P.J. Durack, S.E. Wijffels, T.P. Boyer, "Long-term salinity changes and implications for the global water cycle", in: Ocean Circulation and Climate. A $21^{\text {st }}$ Century Perspective. G. Siedler, S.M. Griffies, J. Gould, J.A. Church (editors). Elsevier, Amsterdam, 2013, ISBN: 978-0-12-391851-2, pp. 727-757.

[6] S. Seitz, R. Feistel, D.G. Wright, S. Weinreben, P. Spitzer, P. de Bievre, Metrological traceability of oceanographic salinity measurement results, Ocean Sci. 7(2011), pp. 45-62.

[7] IOC, SCOR, IAPSO, The international thermodynamic equation of seawater - 2010: Calculation and use of thermodynamic properties. Intergovernmental Oceanographic Commission, Manuals and Guides No. 56, UNESCO (English), 196 pp., Paris. 2010, http://www.TEOS-10.org

[8] R. Feistel, R. Wielgosz, S.A. Bell, M.F. Camões, J.R. Cooper, P. Dexter, A.G. Dickson, P. Fisicaro, A.H. Harvey, M. Heinonen, O. Hellmuth, H.-J. Kretzschmar, J.W. Lovell-Smith, T.J. McDougall, R. Pawlowicz, P. Ridout, S. Seitz, P. Spitzer, D. Stoica, H. Wolf, Metrological challenges for measurements of key climatological observables. Part 1: Overview, Part 2: Oceanic salinity, Part 3: Seawater $\mathrm{pH}$, Part 4: Atmospheric relative humidity, Metrologia (2015), in press.

[9] R. Feistel, D.G. Wright, K. Miyagawa, A.H. Harvey, J. Hruby, D.R. Jackett, T.J. McDougall, W. Wagner, Mutually consistent thermodynamic potentials for fluid water, ice and seawater: a new standard for oceanography, Ocean Sci. 4(2008), pp. 275-291.

[10] R. Pawlowicz, T.J. McDougall, R. Feistel, R. Tailleux, An historical perspective on the development of the Thermodynamic Equation of Seawater - 2010, Ocean Sci. 8(2012), pp. 161-174.

[11] F.J. Millero, R. Feistel, D.G. Wright, T.J. McDougall, The composition of Standard Seawater and the definition of the Reference-Composition Salinity Scale, Deep-Sea Res. I 55(2008), pp. 50-72.

[12] D.G. Wright, R. Pawlowicz, T.J. McDougall, R. Feistel, G.M. Marion, Absolute Salinity, "Density Salinity" and the ReferenceComposition Salinity Scale: present and future use in the seawater standard TEOS-10, Ocean Sci. 7(2011), pp. 1-26.

[13] M. Tanaka, G. Girard, R. Davis, A. Peuto, N. Bignell, Recommended table for the density of water between $0{ }^{\circ} \mathrm{C}$ and $40{ }^{\circ} \mathrm{C}$ based on recent experimental reports, Metrologia 38(2001), pp. 301-309.

[14] A.H. Harvey, R. Span, K., Fujii, M., Tanaka, R.S. Davis, Density of water: roles of the CIPM and IAPWS standards, Metrologia 46(2009), pp. 196-198.

[15] A. Picard, R.S. Davis, M. Gläser, K. Fujii, Revised formula for the density of moist air (CIPM-2007), Metrologia 45(2008), pp. 149-155.
[16] R. Feistel, TEOS-10: A new international oceanographic standard for seawater, ice, fluid water and humid air, Int. J. Thermophys. 33(2012), pp. 1335-1351.

[17] T.J. McDougall, Potential enthalpy: A conservative oceanic variable for evaluating heat content and heat fluxes, J. Phys. Oceanogr. 33(2003), pp. 945-963.

[18] R. Feistel, D.G. Wright, H.-J. Kretzschmar, E. Hagen, S. Herrmann, R. Span, Thermodynamic properties of sea air, Ocean Sci. 6(2010), pp. 91-141.

[19] WMO, Guide to Meteorological Instruments and Methods of Observation. World Meteorological Organisation, Geneva, 2008, ISBN 978-92-63-10008-5.

[20] R. Pawlowicz, D.G. Wright, F.J. Millero, The effects of biogeochemical processes on oceanic conductivity/salinity/density relationships and the characterization of real seawater, Ocean Sci. 7(2011), pp. 363387.

[21] R. Feistel, J.W. Lovell-Smith, O. Hellmuth, Virial approximation of the TEOS-10 equation for the fugacity of water in humid air. Int. J. Thermophys. 36(2015), pp. 44-68.

[22] J.F. Mulligan, G.G. Hertz, An unpublished lecture by Heinrich Hertz: "On the energy balance of the Earth", Am. J. Phys. 65(1997), pp. 36-45.

[23] W. Ingram, A very simple model for the water vapour feedback on climate change. Quart. J. Roy. Met. Soc. 136(2010), pp. 30-40.

[24] R. Feistel, "Water, steam and climate", Proc. 16th Int. Conf. Prop. Water Steam, Greenwich, UK, September 2013.

[25] BIPM, "WMO-BIPM Workshop on Measurement Challenges for Global Observation Systems for Climate Change Monitoring: Traceability, Stability and Uncertainty", WMO Headquarters, Geneva, Switzerland, 2010, ISBN 13 978-92-822-2239-3.

[26] R. Feistel, A Gibbs function for seawater thermodynamics for -6 to $80{ }^{\circ} \mathrm{C}$ and salinity up to $120 \mathrm{~g} / \mathrm{kg}$, Deep-Sea Res. I, 55(2008), pp. 1639-1671.

[27] R. Feistel, G.M. Marion, R. Pawlowicz, D.G. Wright, Thermophysical property anomalies of Baltic seawater, Ocean Sci. 6(2010), pp. 949-981.

[28] F.J. Millero, K. Kremling, The densities of Baltic waters, DeepSea Res. 23(1976), pp. 1129-1138.

[29] K. Kremling, New method for measuring density of seawater, Nature 229(1976), pp. 109-110.

[30] H. Wolf, Determination of water density: limitations at the uncertainty level of $1 \times 10^{-6}$, Accred. Qual. Assur. 13(2008), pp. 587-591.

[31] R. Feistel, S. Weinreben, H. Wolf, S. Seitz, P. Spitzer, B. Adel, G. Nausch, B. Schneider, D.G. Wright, Density and Absolute Salinity of the Baltic Sea 2006-2009, Ocean Sci. 6(2010), pp. 324.

[32] IAPWS, Thermophysical Properties of Seawater. IAPWS Certified Research Need - ICRN 16 (2014), http://www.iapws.org/icrn.html. 